\title{
УПРАВЛЕНИЕ ФИНАНСОВЫМИ ОБЯЗАТЕЛЬСТВАМИ КАК ЧАСТЬ СИСТЕМЫ СТРАТЕГИЧЕСКОГО ПЛАНИРОВАНИЯ КОМПАНИИ
}

\author{
(С) 2021 Сидорова М.И. \\ доктор экономических наук, доцент, заместитель декана по научной работе \\ Факультета международных экономических отношений, \\ руководитель научно-учебной лаборатории «ANAPLAN (Analitical Planning)» \\ Финансовый университет при Правительстве Российской Федерации, Россия, Москва \\ E-mail: MISidorova@fa.ru \\ (C) 2021 Горошников М. А. \\ студент Факультета международных экономических отношений, \\ Научно-учебная лаборатория «ANAPLAN (Analitical Planning)» \\ Финансовый университет при Правительстве Российской Федерации, Россия, Москва \\ E-mail:183285@edu.fa.ru
}

В данной статье раскрываются основные аспекты формирования финансовых обязательств, их влияние и значение на экономику фирмы, рассматривается важность финансовых обязательств как основного источника финансирования, дается оценка ключевых моментов их администрирования.

Ключевые слова: финансовые обязательства, платежи, задолженность, обязательный платеж, ключевой источник, администрирование, кризисная ситуация, дефолт, финансовая устойчивость.

Финансовое обязательство представляет собой обязательный платеж организации ил предприятия, который обусловлен договорными и финансовыми отношениями.

Структура финансовых обязательств включает в себя:

- оплата товаров и услуг, приобретенных в кредит поставщику;

- обязательные платежи в бюджет;

- начисленная, но невыплаченная заработная плата.

- оплачивается по векселям;

- социальное обеспечение и безопасность;

- перед дочерними и зависимыми обществами;

- по полученным предоплатам;

- перед другими кредиторами [3].

Кредиторская задолженность является одним из основных источников финансирования текущей деятельности. Существенным является то, что в силу различных обстоятельств у компании были средства (активы), за которые она должна была заплатить определенную сумму денег, или были сформированы резервы, которые предполагают возврат денег в будущем. До перевода денежных средств или других разрушительных операций компания использует финансовые ресурсы других лиц. Сальдо пассивов отражается в единой сумме, состоящей из отдельных сальдо.
Обязательства часто являются очень важным источником, и ключевыми моментами их администрирования являются:

- выбор поставщика (в данном случае, где это возможно, надежность поставщика, возможность построения долгосрочных отношений, изменчивость в установлении финансовых и расчетных отношений, наличие различных систем доставки товаров, среднее время доставки и т.д.);

- проверка своевременности платежей (превышение срока оплаты за поставленный товар обычно приводит к штрафам)

- выбор времени расчета с данным кредитором в данной ситуации (в большинстве случаев поставщики продукта, которые естественно заинтересованы в ускорении платежа, предлагают скидку от продажной цены при условии относительно быстрого платежа Дилемма перед компанией) [4].

Полученные авансы возникают, когда получен платеж за доставку материалов или выполнение работы, которую получает издатель, например, при подписке на журнал или когда клиент вносит предоплату за сырье. Полученные авансы представляют собой обязательство возвратить полученный актив или выполнить определенную услугу или выполнить другие договорные обязательства, обычно в течение периода, следующего за отчетным. 
Финансовые обязательства часто являются очень важным источником, и ключевыми моментами их администрирования являются:

- выбор поставщика (в данном случае, где это возможно, надежность поставщика, возможность построения долгосрочных отношений, изменчивость в установлении финансовых и расчетных отношений, наличие различных систем доставки товаров, среднее время доставки и т.д.);

- проверка своевременности платежей (превышение срока оплаты за поставленный товар обычно приводит к штрафам)

- выбор времени расчета с данным кредитором в данной ситуации (в большинстве случаев поставщики продукта, которые естественно заинтересованы в ускорении платежа, предлагают скидку от продажной цены при условии относительно быстрого платежа дилемма перед компанией) [7].

Коммерческий кредит - это кредит, который одна операционная компания предоставляет другому в форме продажи отложенных товаров, причем товар является капиталом [8].

Коммерческий кредит используется для рециркуляции капитала. Целью является ускорение продажи товаров и получения прибыли. Сумма этого кредита ограничена суммой резервного кредита коммерческого капитала. Перевод этих средств возможен только от компаниипоставщика компании-покупателю [9].

Кредиторская задолженность означает получение средств от других компаний, организаций и частных лиц для экономического потока бизнеса. Использование средств, привлеченных в соответствии с существующими условиями и обязательствами, является законным. Однако в большинстве случаев обязательства возникают в результате нарушения платежной дисциплины. В связи с этим компании не выполняют обязательств перед поставщиками, поскольку они получили товары, которые еще не были оплачены, по выпущенным векселям и полученным авансовым платежам. Если сроки уплаты налоговых платежей не соблюдены, задолженность по уплате налоговым органам [10].

В современных условиях большая часть этого связана с торговой кредиторской задолженностью, а также с поставками и услугами.

Задолженность связана с формированием дебиторской задолженности и является основным источником покрытия. Поэтому считается, что обязательства не должны быть ниже требований.
Такая ситуация была бы крайне неоправданной, поскольку средства, временно отвлеченные и временно введенные в обращение, не должны быть разного порядка. Обязательства должны быть погашены компанией независимо от суммы дебиторской задолженности.

Финансовые обязательства являются частью финансовых отношений, связанных с движением денежных средств, и основаны на переводе средств компаниям для финансово-хозяйственной деятельности.

Краткосрочные обязательства - все виды заимствований, используемые юридическим лицом со сроком погашения основной суммы долга до одного года (краткосрочные банковские кредиты; краткосрочные кредиты от небанковских организаций; краткосрочные облигации, выпущенные компанией; выпущенные счетафактуры; полученные товары; различные формы внутренних кредитных обязательств и т.д.).

Согласно МСФО, финансовым обязательством является любое договорное обязательство:- передача денег или других финансовых активов другой компании; или обмен финансовых инструментов с другой компанией на условиях, которые потенциально убыточны.

Как элемент макроэкономической системы, оснащенной в рыночной экономике не только правами юридического лица, но и основным правом - правом на экономическую независимость - компания может оказаться в кризисной ситуации. Внешним признаком начала кризисной ситуации в компании является ее несостоятельность, которая определяется неудовлетворительным уровнем показателей платежеспособности. Другими словами, невозможность выполнения своих обязательств перед кредиторами, поставщиками и оплаты счетов за полученные товары является признаком возможной несостоятельности компании [11].

Управленческие решения должны учитывать не только высокую прибыльность, но и проблемы существования своих сотрудников, а также потребителей, для которых существует компания и чьи фактические потребности удовлетворяются, требуют функционирования компании.

Вероятность дефолта - гибель компании (банкротство) довольно велика. Показатели платежеспособности, которые не соответствуют значениям по умолчанию, являются внешними признаками того, что компания является неблагоприятной. 

блемы:

Существует два подхода к решению этой про-

- первый - это «компенсация», когда кредиторы вовлечены в экономическую жизнь компании, реструктуризацию задолженности и многое другое.

- второй - это «конкуренция», которая предполагает процедуру урегулирования требований кредиторов к неплатежеспособному должнику, при исполнении которой ликвидируется компания - экономическая деятельность заканчивается после окончания конкурса [12].

Но с профилактикой лучше и дешевле иметь дело. Поэтому так важно определить ситуацию в компании до начала кризисной ситуации, а еще полезнее проводить регулярную оценку ситуации. Это особенно важно для тех, кто контролирует бизнес в компании. «Подобно капитану судна, капитану бизнеса нужна система показателей экономической эффективности, которая дает ему информацию о том, как лучше всего сравнить ситуацию в его компании в прошлом, и в настоящее время сравнивается с ситуацией компаний самых сложных конкурентов.» Необходимость регулярной оценки ситуации в компании, особенно с точки зрения ее рентабельности, важна не только для компаний в соседней зоне несостоятельности или в затруднительном положении, но и для компаний, у которых «все хорошо» и значения традиционных показателей в экономике нормальный диапазон. Это важно для оценки корпоративной стратегии и управления. Корпоративная стратегия направлена на обеспечение надежного преимущества перед конкурентами, т.е. Завоевание истинного и полного успеха компании. Оценка бизнес-стратегии определяет не только то, что должно быть достигнуто и будет ли оно достигнуто, но также и потенциальные возможности сегодня и в будущем".

Важную роль в оценке ситуации в компании играют независимые аудиторские проверки с учетом следующего. Аудит основан на предположении, что компания находится в постоянном режиме работы и продолжит свою деятельность в ближайшее время. Руководство компании, формально, то есть с помощью финансовых отчетов, не обязано доказывать соответствие этого предположения, например, путем планирования денежных доходов на следующий период. И при таком подходе существует риск неожиданного краха компании. Поэтому, в дополнение к критериям, вытекающим из обязательной отчетности, необходимо проводить активный и долгосрочный мониторинг состояния. Кроме того, оценка деятельности компании должна быть направлена на выявление факторов, ограничивающих успех, выявление проблем, которые мешают компании и препятствуют ее развитию.

Финансовая стабильность и эффективность компании связаны с такой концепцией, как экономическая независимость.

Финансовая устойчивость (баланс) характеризуется традиционными и общепринятыми показателями ликвидности. Получение прибыли показывает прибыль над затратами и является одной из основных целей предпринимательской деятельности. В качестве критерия можно использовать максимизацию прибыли или максимизацию прибыльности, два независимых и автономных критерия, которые предполагают различные меры для достижения этих целей.

\section{Библиографический список}

1. Агапитова Л.Г. Управление финансовыми ресурсами и финансовое состояние хозяйствующего субъекта // Вестник Курганской ГСХА. 2013. - № 1 (5). - С. 4-6.

2. Аньшин В.М., Царьков И. Н., Яковлева А. Ю. Бюджетирование в компании: Современные технологии постановки и развития: Учеб. пособие. - М.: Дело, 2015.

3. Васильева Е.А. Маркетинговая логистика как фактор повышения конкурентоспособности предприятия // Современные тенденции в экономике и управлении: новый взгляд, 2014. - № 26.

4. Воловник А.Д., Уланов С. В., Опарин Д. Ж. Методы оптимизации управления финансовыми ресурсами предприятия // Аудит и финансовый анализ, 2013. - № 4. - С. 324-356.

5. овалева А.М., Лапуста М. Г., Скамай Л.Г. Финансы фирмы: Учебник. - М.: ИНФРА-М, 2015.

6. Козлова М.А. Об управлении финансовыми ресурсами коммерческой организации // Вестник СевероКавказского федерального университета, 2011. - № 4. - С. 229-233.

\footnotetext{
* Храмова Т. М.Бюджетирование в управлении финансовыми ресурсами ВУЗа // Экономика образования, 2009. - № $1 .-$ C. $88-100$.
} 
7. Космачева Н. М. Вопросы развития инфраструктуры малого и среднего бизнеса: обеспечение доступа к финансовым ресурсам // Вестник Ленинградского государственного университета им. А. С. Пушкина, 2012. Т. 6. - № 2. - C. 19-33.

8. Кулагина М.Е. Использование современных инструментов в системе управления финансовыми ресурсами // Финансы и кредит, 2019. - № 3 (339). - С. 19-23.

9. Остапенко Л. М. Эволюция понятия «финансовые ресурсы» и современные подходы к определению понятия «финансовые ресурсы предприятия» // Вестник современной науки, 2016. - № 1-1 (13). - C. $101-104$.

10. Рахимов Т.Р., Жданова А.Б., Спицын В.В. Денежное обращение, финансы и кредит. - Томск: Издательство Томского политехнического университета, 2019. - 204 с.

11. Ситников А.А., Ситников С.Г. Анализ использования оперативного менеджмента в финансовом менеджменте // Электронный научный журнал, 2015. - № 2 (2). - С. 658-662.

12. Финансы: Учебник / А. С. Нешитой, Я. М. Воскобойников. - 10-е изд. - М.: Издательско-торговая корпорация «Дашков и $\mathrm{K}^{\circ}$, 2012. - 528 с. 3 